University of Nebraska - Lincoln

DigitalCommons@University of Nebraska - Lincoln

$9-14-2005$

\title{
The coadsorption and interaction of molecular icosahedra with mercury
}

\author{
C.C. Ilie \\ University of Nebraska-Lincoln \\ Snjezana Balaz \\ University of Nebraska-Lincoln, sbalaz@ysu.edu \\ Luis G. Rosa \\ University of Nebraska-Lincoln, luis.rosa13@upr.edu \\ Jun Zhang \\ University of Nebraska-Lincoln, jzhang5@unl.edu \\ P. Lunca-Popa \\ University of Nebraska-Lincoln \\ See next page for additional authors
}

Follow this and additional works at: https://digitalcommons.unl.edu/physicsdowben

Part of the Physics Commons

Ilie, C.C.; Balaz, Snjezana; Rosa, Luis G.; Zhang, Jun; Lunca-Popa, P.; Bianchetti, C.; Tittsworth, R.; Brand, Jennifer I.; Doudon, B.; and Dowben, Peter A., "The coadsorption and interaction of molecular icosahedra with mercury" (2005). Peter Dowben Publications. 117.

https://digitalcommons.unl.edu/physicsdowben/117

This Article is brought to you for free and open access by the Research Papers in Physics and Astronomy at DigitalCommons@University of Nebraska - Lincoln. It has been accepted for inclusion in Peter Dowben Publications by an authorized administrator of DigitalCommons@University of Nebraska - Lincoln. 


\section{Authors}

C.C. Ilie, Snjezana Balaz, Luis G. Rosa, Jun Zhang, P. Lunca-Popa, C. Bianchetti, R. Tittsworth, Jennifer I. Brand, B. Doudon, and Peter A. Dowben 


\title{
The coadsorption and interaction of molecular icosahedra with mercury
}

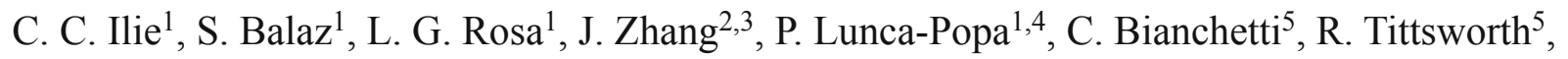 \\ J. I. Brand ${ }^{4}$, B. Doudin ${ }^{1}$, P. A. Dowben ${ }^{1, *}$ \\ ${ }^{1}$ Department of Physics and Astronomy and the Center for Materials Research and Analysis, Behlen Laboratory of Physics, University of \\ Nebraska-Lincoln, Lincoln, NE 68588-0111, USA \\ ${ }^{2}$ Department of Physics, Florida International University, Miami, FL 33199, USA \\ ${ }^{3}$ Center for Materials Research and Analysis, 116 Brace Laboratory, University of Nebraska-Lincoln, Lincoln, NE 68588-0111, USA \\ ${ }^{4}$ College of Engineering and Technology, N104 Walter Scott Engineering Center, $17^{\text {th }} \&$ Vine Streets, University of Nebraska - Lincoln, Lincoln, \\ Nebraska 68588-0511, USA \\ ${ }^{5}$ J. Bennett Johnston Sr. Center for Advanced Microstructures and Devices, 6980 Jefferson Highway, Louisiana State University, Baton Rouge, \\ LA 70806, USA \\ * Correspondence - Email: pdowben@unl.edu
}

\begin{abstract}
We have investigated the changes in the electronic structure of molecularly adsorbed orthocarborane films, as a function of $\mathrm{Hg}$ co-adsorption, using photoemission. The interaction between $\mathrm{Hg}$ and molecular orthocarborane is weak and results in the formation of some small aggregates of $\mathrm{Hg}$. This behavior is very different from alkali metals interaction with molecular carborane films and the interaction of $\mathrm{Hg}$ with semiconducting boron carbide films. $\mathrm{Hg}$ doping of semiconducting boron carbide may decrease the activation barrier for intrinsic carrier mobility, but does not significantly increase the number of carriers.
\end{abstract}

\section{Introduction}

Semiconducting boron carbide represents a new class of semiconducting materials with potential applications in neutron detection and radioactive decay calorimetry [1-5]. Neutron detectors with boron carbide have begun to attract attention [7-9]. Boron has high cross section for neutrons at lower energies, with capture processes:

$\mathrm{n}+{ }^{10} \mathrm{~B} \rightarrow{ }^{7} \mathrm{Li}+{ }^{4} \mathrm{He}+\gamma$

$\mathrm{n}+{ }^{10} \mathrm{~B} \rightarrow{ }^{7} \mathrm{Li}+{ }^{4} \mathrm{He}_{\mathrm{n}+} 10_{\mathrm{B} \rightarrow}{ }^{11_{\mathrm{B}+\gamma}}$

Several isotopes of mercury $(\mathrm{Hg})$ have a high neutron cross section at higher neutron energies [10]. The combination of mercury doped boron carbide could then be a candidate for neutron detectors over a wider range of neutron energies. The relevant large neutron capture processes by $\mathrm{Hg}$ include [10]:

$\mathrm{n}+{ }^{196} \mathrm{Hg} \rightarrow{ }^{195} \mathrm{Hg}+2 \mathrm{n} \mathrm{n}+{ }^{196} \mathrm{Hg} \rightarrow$

${ }^{195} \mathrm{Hg}+2 \mathrm{n}+\gamma$

$\mathrm{n}+{ }^{198} \mathrm{Hg} \rightarrow{ }^{197} \mathrm{Hg}+2 \mathrm{n}$

$\mathrm{n}+{ }^{198} \mathrm{Hg} \rightarrow{ }^{197} \mathrm{Hg}+2 \mathrm{n}+\gamma$

$\mathrm{n}+{ }^{204} \mathrm{Hg} \rightarrow{ }^{203} \mathrm{Hg}+2 \mathrm{n}$

$\mathrm{n}+{ }^{204} \mathrm{Hg} \rightarrow{ }^{204} \mathrm{Au}+\mathrm{p}$
The isotopes ${ }^{196} \mathrm{Hg}(0.15 \%),{ }^{198} \mathrm{Hg}$ $(10.1 \%)$, and ${ }^{204} \mathrm{Hg}(6.8 \%)$ are all stable and commercially available. Note that the product ${ }^{197} \mathrm{Hg}$ provides further radioactive decay products. Thus characterization and understanding of $\mathrm{Hg}$ doping of semiconducting boron carbide as well as the coadsorption of mercury and molecular icosahedral carboranes, like closo-1,2-dicarbadodecaborane, $\mathrm{C}_{2} \mathrm{~B}_{10} \mathrm{H}_{12}$ (commonly known as orthocarborane), are key for developing boron based solid state neutron detectors.

Both transition metal doping of semiconducting boron carbides and the coadsorption of metals with molecular carborane films have been previously investigated. $\mathrm{Hg}$ and alkali metal mixtures with molecules have a long history in the study of non-metal to metal transitions $[11,12]$. This has been extended to the study of metal coadsorption with icosahedral molecular carboranes [13$16]$, in part motivated by the large highest occupied to lowest unoccupied molecular orbital (HOMO-LUMO) band gap of the icosahedral carboranes and their nearly spherical shape [13]. Orthocarborane has qualities which make it an interesting material when used in studying the coadsorption behavior of different metals with the molecular films. For example, the HOMOLUMO orbitals can be easily identified, and the orthocarborane adsorption is molecular. Alkali metal mixtures with molecular carboranes have been studied through the nonmetal to metal transition [13-15]. Hg and molecular carborane mixtures [16] have not lended themselves to studies of the nonmetal to metal transition as homogeneous mixtures of the carborane molecules and mercury do not readily form.

Because of the interest in forming semiconducting boron carbide homo-junction devices [17], transition metal doping of semiconducting boron carbides has been more actively investigated. The iron [18-21], vanadium [21], chromium [21] and nickel [17, 21-24] doping of boron carbides is documented. All of these latter transition metal dopants dope boron and boron carbides $n$-type. A mechanism 
has not yet been put forward for the donor state accumulation that accompanies transition metal doping [22, 24]. Models for increasing donor and acceptor state densities are complicated by the observation that there are several polytypes of similar composition boron carbides (studies in some detail for the nominally $\mathrm{C}_{2} \mathrm{~B}_{10}$ semiconducting boron carbides $[4,25,26])$ and both $n$-type and $p$-type semiconducting boron carbides are possible without transition metal doping.

In the absence of transition metal doping, it is clear that to some extent the behavior of molecular carborane films does provide some indication of the properties of dehydrogenated $\mathrm{C}_{2} \mathrm{~B}_{10}$ icosahedra that are the building blocks of semiconducting boron carbide [4], in spite of the vastly larger HOMOLUMO band gap of the molecular films when compared to the direct band gap of the various semiconducting boron carbides [25]. We show evidence here that neither the molecular analogs, nor the associated hydrogenated molecular species (including the main group source compounds for fabricating semiconducting boron carbide) provide a good indicator of the metal doped semiconducting boron carbide properties. Mercury $(\mathrm{Hg})$, however, does appear to interact with dehydrogenated semiconducting boron carbide films, as discussed herein. Given that the semiconducting boron carbide has unsaturated bonds, because it is formed from a largely dehydrogenated $\mathrm{C}_{2} \mathrm{~B}_{10}$ icosahdra, this contrast between metal doping of molecular hydrogenated icosahedra that are the basis of the closo-dicarbadodecaboranes, $\mathrm{C}_{2} \mathrm{~B}_{10} \mathrm{H}_{12}$, and semiconducting boron carbide is not surprising.

\section{Experimental and theoretical details}

The photoemission experiments were performed in a UHV system equipped with a hemispherical energy analyzer. The photon-energy source employed was the $1 \mathrm{GeV}$ Aladdin ring of Synchrotron Radiation Center at Stoughton, Wisconsin. The light was dispersed by a four meter, normal incidence monochromator and the photoemission spectra were taken at a photon energy of $35 \mathrm{eV}$. The highly plane polarized light was incident on the sample in a largely $p$-polarized con- figuration, $65^{\circ}$ off normal while the photoemission spectra were obtained at normal emission. The light source and the electron energy analyzer had a combined energy resolution between 40 and $80 \mathrm{meV}$. All the binding energies are referenced to the Fermi energy of the clean copper substrate.

The copper substrate, used in the photoemission experiments, was cleaned by $\mathrm{Ar}^{+}$ion sputtering before each adsorption experiment and annealed at 850 $\mathrm{K}$. The mercury was coadsorbed at 180 $\mathrm{K}$ after the adsorption of orthocarborane onto the $\mathrm{Cu}(100)$ substrate. The coverage was determined by the attenuation of the substrate photoemission features as was undertaken in previous work $[27,28]$ including previous efforts on the coadsorption of $\mathrm{Hg}$ and carboranes [16]. The mercury exposure is denoted in terms of Langmuirs where $1 \mathrm{~L}=10^{-6}$ Torr-seconds. The purity of orthocarborane (closo-1,2-dicarbadodecaborane, $\mathrm{C}_{2} \mathrm{~B}_{10} \mathrm{H}_{12}$ ) was higher than $98 \%$, as determined by infrared adsorption, nuclear magnetic resonance, and mass spectroscopy measurements. Both orthocarborane and mercury were admitted to the chamber through standard leak valves.

Transport measurements were undertaken for decomposed (semiconducting) orthocarborane films between the room temperature down to $3 \mathrm{~K}$ on both gold and copper substrates. The boron carbide semiconductor films were formed following plasma enhanced chemical vapor deposition (PECVD) in custom $13.56 \mathrm{MHz}$ radio frequency parallel plate reactors, as described previously [29, 30]. This deposition technique is considered quite effective as PEVCD semiconducting boron carbide, formed from the orthocarborane source molecule, has been used to make boron carbide homojunction diodes [22-24], Esaki tunnel diodes [22-24], and a boron carbide heteroisomeric diode [4].

The semiconducting boron carbide films were exposed to mercury vapor in an isolated vacuum system for several weeks, and the presence of a low concentration was determined by $\mathrm{X}$ ray fluorescence by the presence of $L$ shell fluorescence lines of mercury with X-ray radiation at $12600 \mathrm{eV}$ for the primary excitation, dispersed by the double crystal monochromator at the Center for Advanced Microstructures and Devices synchrotron in Ba- ton Rouge, Louisiana. X-ray adsorption fine structure near the $\mathrm{Hg} L_{\text {III }}(2$ $p_{3 / 2}$ subshell) edge (XANES) were undertaken on the same beamline.

The ground state theoretical model calculations of the three isomeric carboranes were performed using the HyperChem package using PM3-NDO (neglected differential overlap) calculations with the PM3 basis set $[31,32]$. These semi-empirical model calculations of the electronic structure were performed following geometry optimization and the lowest restricted Hartree Fock (RHF). The energy states and their symmetries (the irreducible representations) were obtained. Theoretical calculations of the energy for the configuration of one molecule of orthocarborane and one atom of mercury were also undertaken.

\section{Mercury interactions with molec- ular carborane films}

Following the adsorption of closo-1,2dicarbadodecaborane, $\mathrm{C}_{2} \mathrm{~B}_{10} \cdot \mathrm{H}_{12}$ (orthocarborane) on $\mathrm{Cu}(100)$ at $180 \mathrm{~K}$, the highest occupied molecular orbital (HOMO) appears in the photoemission spectra at an initial binding energy of $5.7 \mathrm{eV}$ below the Fermi level, while the lowest unoccupied molecular orbital (LUMO) is observed at roughly $4.25 \mathrm{eV}$ with respect to the Fermi level $\left(E-E_{\mathrm{F}}\right)[14,15,33]$. This HOMOLUMO gap is generally consistent with theory [14-16, 33]. In Fig. 1, we present the photoemission spectra of one molecular monolayer of orthocarborane adsorbed onto $\mathrm{Cu}(100)$ substrate at $180 \mathrm{~K}$ before and after coadsorption of mercury. The orthocarborane molecular orbital induced photoemission features are evident at binding energies of 5.7, 6.3, 6.8, 8.2,11.2, and $12.3 \mathrm{eV}$. The substrate copper $d$-bands are evident in the spectra between 2 and $4 \mathrm{eV}$ binding energy. While many of the molecular orbitals result in overlapping photoemission features, a number of features are easily attributable to the molecular orbitals of orthocarborane [33, 34], and the photoemission is characteristic of adsorbed molecular orthocarborane. (The photoemission features resulting from the molecular orbitals do evolve into the bands of semiconducting boron carbide with decomposition $[34,35]$.)

With increasing $\mathrm{Hg}$ exposure to the carborane film at $180 \mathrm{~K}$, the $\mathrm{Hg}$ induced photoemission features appear at 


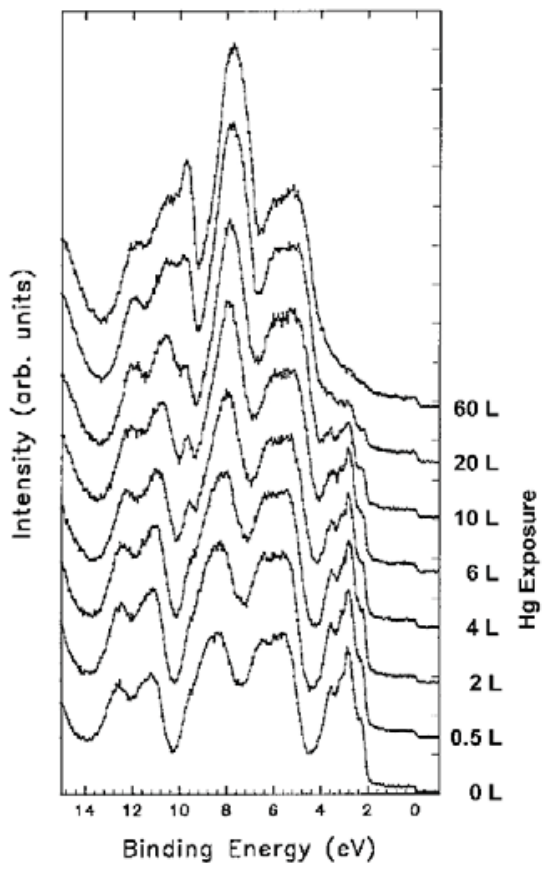

FIGURE 1 Photoemission spectra of one molecular monolayer of orthocarborane on $\mathrm{Cu}$ (100), at $T=180 \mathrm{~K}$, as a function of mercury exposure. The photon energy is $35 \mathrm{eV}$. The mercury induced photoemission features (7.6 and 9.6 $\mathrm{eV})$ are identified as the $\mathrm{Hg} 5 d_{5 / 2}$ and $5 d_{3 / 2}$ shallow core levels and those features seem to remain unchanged in intensity with increasing mercury exposure. The photoelectrons are collected normal to the surface, and the light incidence angle is $65^{\circ}$ (a largely $p$-polarized configuration).

binding energies of $7.6 \mathrm{eV}$ and $9.6 \mathrm{eV}$, as seen in Fig. 1. These photoemission features are identified as $\mathrm{Hg} 5 d_{5 / 2}$ and $\mathrm{Hg} 5 d_{3 / 2}$ shallow core levels, respectively. The $\mathrm{Hg} 5 d_{5 / 2}$ shallow core level and the orthocarborane features at $8.2 \mathrm{eV}$ overlap, consequently the $\mathrm{Hg} 5 d_{5 / 2}$ features initially appear broader at low $\mathrm{Hg}$ exposures (Fig. 1). As summarized in Fig. 2, the intensity of copper features decreases while the intensity of mercury features increase with mercury coadsorption. The orthocarborane intensity remains largely unchanged in spite of the increase in $\mathrm{Hg}$ concentration in the molecular film, i.e. as the $\mathrm{Hg} 5 d_{5 / 2}$ core level intensity increases. This tends to suggest that the mercury does NOT wet the orthocarborane film surface. An absence of wetting and an absence of a uniform distribution of $\mathrm{Hg}$ in the carborane film indicate that the interaction of $\mathrm{Hg}$ with orthocarborane is very weak.

Another signature of weak interactions between the carboranes and thecoadsorbed mercury is indicated by the

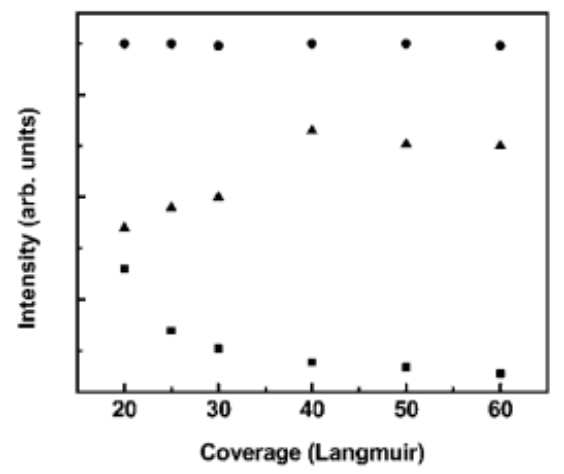

FIGURE 2 The photoemission intensities of the orthocarborane $(\bullet), \mathrm{Hg} 5 d_{3 / 2}$ core level ( $\boldsymbol{\Delta}$ ) and, the $\mathrm{Cu} 3 d$ bands (-) as a function of $\mathrm{Hg}$ exposure to a monolayer of orthocarborane film on $\mathrm{Cu}(100)$ at $180 \mathrm{~K}$. Exposure of orthocarborane on $\mathrm{Cu}(100)$ substrate to mercury vapor results in the suppression of the copper $3 d$ band features and the increase (in intensity) of the mercury induced features.

shifts in binding energy of both the orthocarborane photoemission features and the shallow core levels of mercury. A small increase in the $\mathrm{Hg}$ shallow core level binding energies concomitant with the decrease in orthocarborane molecular orbital binding energies was observed with increased concentrations of $\mathrm{Hg}$, as plotted in Fig. 3. The shift in binding energy of the mercury $5 d$ levels and the binding energy changes in orthocarborane molecular orbitals have about the same magnitude but the photoemission binding energies for the two species shift opposite direction with respect to the Fermi level: $\mathrm{Hg}$ towards slightly greater binding energies and orthocarborane molecular orbital photoemission features to slightly smaller binding energies. This indicates that the coadsorption of mercury may result in a small charge transfer between the orthocarborane and the mercury, bearing in mind that increased screening in the photoemission final state [13] cannot be excluded. Hybridization between the mercury $5 d$ core level and the molecular orbitals of the orthocarborane clusters is, nonetheless, indicated. The shift in binding energies of the mercury $5 d$ core level and the molecular orbitals of the orthocarborane saturate at about 20-25 L of $\mathrm{Hg}$ coverage. The small shift in photoemission intensities and photoemission binding energies implies that the interaction between orthocarborane and mercury is weak.

The $\mathrm{Hg} 5 d_{5 / 2}$ shallow core level does not exhibit the narrow width of in-

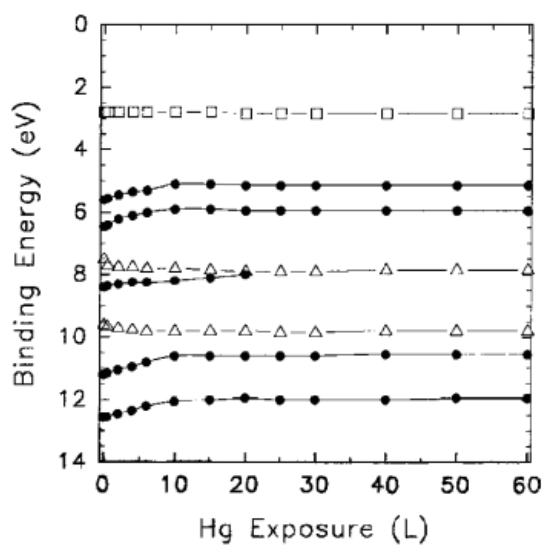

FIGURE 3 The binding energies of the orthocarborane (circles), mercury (triangles), and copper (square) induced features as a function of mercury exposure.

sulating $\mathrm{Hg}$ films nor atomic $\mathrm{Hg}$ [36, 37], rather the $\mathrm{Hg} 5 d_{5 / 2}$ shallow core level exhibits the width of a more metallic $\mathrm{Hg}$ [13]. Given that the photoemission cannot be reconciled with $\mathrm{Hg}$ adsorption wetting the surface of the carborane film, we must conclude that at the higher coverages, $\mathrm{Hg}$ is aggregating into small metallic clusters, or as suggested in earlier work [16], diffusing to the copper carborane interface. Using the explanation that the $\mathrm{Hg}$ accumulates at the orthocarborane copper surface interface does not, however, address the small carborane molecular orbital binding energy shifts to smaller binding energies, as seen in Fig. 3 .

We conclude that some $\mathrm{Hg}$ forms aggregates, most likely on the surface of the carborane film, but not dispersed in the carborane molecular film uniformly. This is to say that the microstructure adopted by the $\mathrm{Hg}$ orthocarborane mixture must be more representative of a weakly immiscible solid solution as occurs when the metal either does not interact very much with the molecular species compared to the self interaction. The result is the formation of small clusters/islands or droplets. A strongly immiscible solid solution resulting from a strongly repulsive interaction between the metal and molecule can be now excluded.

In either the case of $\mathrm{Hg}$ cluster formation within the film or $\mathrm{Hg}$ droplets on top of the film, the surrounding metallic mercury would act to "screen" the photoemission final state resulting from the molecular carboranes. This results in smaller molecular orbital bind- 
ing energies with increasing $\mathrm{Hg}$ coverage, as is observed. A combination of these two scenarios (droplets and inclusions) for the co-adsorption of $\mathrm{Hg}$ and the icosahedral molecule closo1, 2 dicarbadodecaborane (orthocarborane) must be considered to explain the absence of significant increases in the width of orthocarborane molecular orbital photoemission features. The evidence for metallic mercury, from the $\operatorname{Hg} 5 d_{5 / 2}$ core level widths does not suggest that mercury atoms may form a lattice which weakly interacts with orthocarborane lattice, or $\mathrm{Hg}$ may form a wetting surfactant layer and a layer between the $\mathrm{Cu}$ substrate and orthocarborane molecular film which would easily explain a uniform shift in the molecular orbital photoemission binding energies. In this regard, $\mathrm{Hg}$ is very different from the more homogeneous mixtures formed with some metals and molecularly chemisorbed species [14-16, 38-49].

\section{Does Hg cause dehydrogenation of molecular carboranes?}

Given there is interaction between the $\mathrm{Hg}$ and the carborane film, the nature of this interaction could be weak van der Waals type of interaction, or a stronger interaction such as chemical bond following partial dehydrogenation of the carborane. Molecular analogs of mercury and orthocarborane are known [50]. Therefore is dehydrogenation possible, if such mercury bridge bonding between carborane molecules occurs in the presence of mercury vapor? In order to ascertain whether the coadsorption of $\mathrm{Hg}$ with orthocarborane results in the formation of $\mathrm{Hg}$ carborane complexes like those proposed by Hawthorne and coworkers [50], we have undertaken molecular orbital calculations of mercuracarborand-3,2, and mercuracarborand-4, 1, as indicated in Fig. 4.

From our molecular orbital calculations, when compared to molecular orthocarborane, it is clearly evident that the Hg-orthocarborane complexes have a much smaller highest occupied to lowest unoccupied molecular orbital (HOMO-LUMO) gap. Indeed, the HOMO-LUMO gap closure becomes more pronounced with increasing numbers of bridge bonding mercury atoms, as indicated in Fig. 4. This

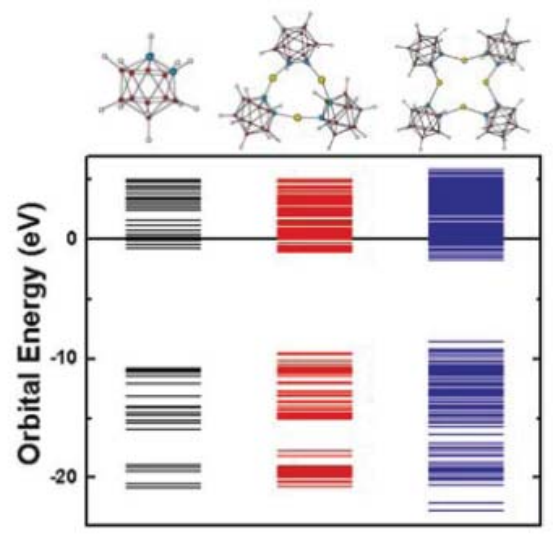

FIGURE 4 Theoretical calculations of highest occupied molecular orbital (HOMO) and lowest unoccupied molecular orbital (LUMO) gap and adjacent molecular orbitals in terms of orbital energies. The HOMO-LUMO gap closes with increased number of bridge bonding $\mathrm{Hg}$ atoms, as indicated.

HOMO-LUMO gap closure, by as much as $3 \mathrm{eV}$ or more, is not observed in the photoemission. As seen in Fig. 1 and summarized in Fig. 2, no pronounced increase in density of states towards smaller binding energies, and no molecular orbitals with significantly smaller binding energies than those directly attributable to orthocarborane, are observed. Furthermore, the $\mathrm{Hg}$ $5 d_{5 / 2}$ line width remains more narrow than can be explained if there were strong chemical bonds formed (while still broader than can be explained by atomic mercury or noninteracting mercury atoms). Therefore, reactions like

$\mathrm{Hg}+\left(\mathrm{C}_{2} \mathrm{~B}_{10} \mathrm{H}_{12}\right) 2 \rightarrow\left(\mathrm{C}_{2} \mathrm{~B}_{10} \mathrm{H}_{11}\right) 2 \mathrm{Hg}$

are unlikely under our experimental conditions and dehydrogenation is also unlikely. Indeed, the inorganic synthesis suggests this Hg-carborane complex formation under ultra high vacuum conditions is unlikely, as Hawthorne and coworkers [50] used closo-1,2- $\mathrm{Li}_{2}-1,2 \quad \mathrm{C}_{2} \mathrm{~B}_{10} \mathrm{H}_{10}$ with the mercuric ion salts of a corresponding halide ion to form $\mathrm{Hg}$ bridge bonded carborane complexes.

Theory suggests that $\mathrm{Hg}$ interaction with molecular carboranes is a repulsive interaction. In Fig. 5, we have plotted the calculated repulsive interaction energy as a function of $\mathrm{Hg}$ to orthocarborane distance. The repulsive interaction, in the absence of dehydrogenation, is to be expected. Mercury is not a reactive metal, having two valence electrons in the occupied

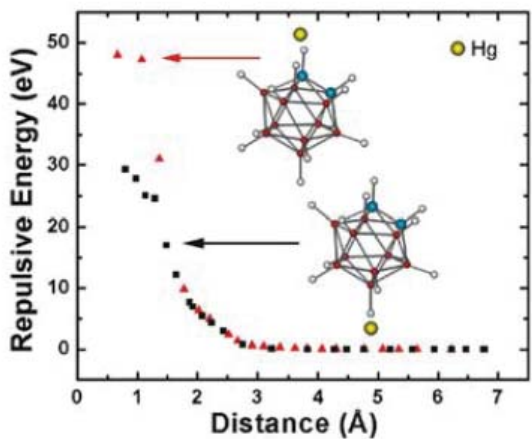

FIGURE 5 The calculated repulsive energy of the orthocarborane in the presence of one atom of mercury situated at two different "starting" positions. The positive energy indicates that the interaction is repulsive.

$6 s$ atomic orbital and large orbital energy separation of more than $4 \mathrm{eV}$ to the unoccupied $6 p$, while orthocarborane is a fairly stable cage molecule. The repulsive interaction is consistent with our observations that $\mathrm{Hg}$ does not "wet" the molecular carborane film.

\section{Does mercury dope semiconduct- ing boron carbide?}

The decomposition of orthocarborane does lead to the formation of a semiconducting boron carbide and is easily doped with nickel [17, 22-24, 51]. Given the small interaction between $\mathrm{Hg}$ and the molecular film, at issue is whether $\mathrm{Hg}$ dopes the semiconducting boron carbide resulting from the dehydrogenation of orthocarborane. To address this issue, we undertook transport measurements on the decomposed orthocarborane films, i.e. semiconducting boron carbide, on an insulating substrate both in the absence and in the presence of a mercury atmosphere and following extensive exposure to $\mathrm{Hg}$ vapor. If the mercury dopes semiconducting boron carbide, then a decrease in resistance is expected, similar to the observations obtained following nickel doping of semiconducting boron carbide [22].

Due to the inert character of mercury [13], of particular concern is if mercury vapors interact with the boron carbide film. Fluorescence studies carried out on semiconducting boron carbide films after extensive mercury vapor exposure indicated the presence of $\mathrm{Hg}$ in the boron carbide film. The data presented in Fig. 6 reveals 


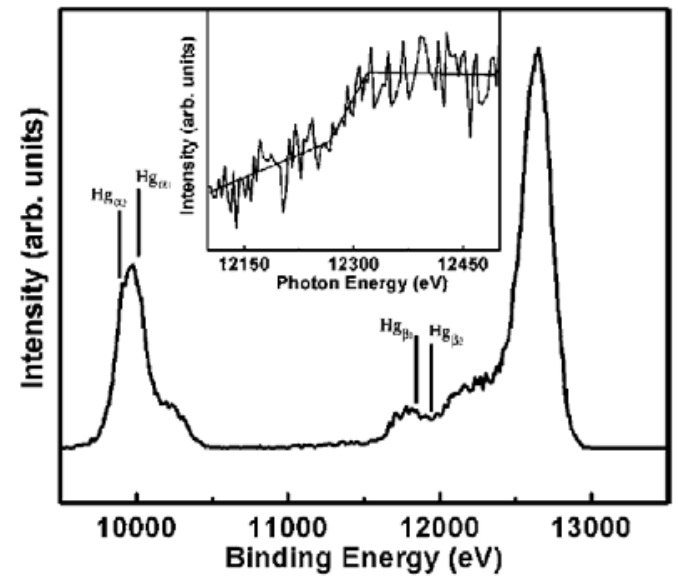

FIGURE 6 Fluorescence data indicating the presence of mercury in semiconducting boron carbide films exposed to mercury vapor. The expected X-ray fluorescence $L$ lines of $\mathrm{Hg}$ : $L_{\alpha 1}$ $=9,988.6 \mathrm{eV}, L_{\alpha_{2}}=9,897.6 \mathrm{eV}, L_{\beta_{1}}=$ $11,822.6 \mathrm{eV}$, and $L_{\beta_{2}}=11,924.1 \mathrm{eV}$, are indicated. The peak on far right is due to the incident radiation. The inset to the figure shows the weak absorbance at the $L_{3} 2 p_{3 / 2}$ subshell of $\mathrm{Hg}$ at $12,284.0 \mathrm{eV}$.

emissions attributable to the various $L$ subshells of mercury with the incident scattering resulting in an intense peak on far right of the X-ray fluorescence spectrum. More specifically, the energies of X-ray emission lines were observed at approximately $10,000 \mathrm{eV}$, $10,250 \mathrm{eV}, 11,750 \mathrm{eV}, 12,200 \mathrm{eV}$, with the strong emission lines at $10,000 \mathrm{eV}$ and $11,750 \mathrm{eV}$ reasonably consistent with the expected X-ray fluorescence $L$ lines of Hg: $L_{\alpha 1}=9,988.6 \mathrm{eV}, L_{\alpha 2}=$ 9,897.6 eV, $L_{\beta 1}=11,822.6 \mathrm{eV}$, and $L_{\beta 2}$ $=11,924.1 \mathrm{eV}$. The $\mathrm{Hg}$ content in the semiconducting boron carbide films remains very low, even after weeks of exposure to $\mathrm{Hg}$ vapor under vacuum, but some X-ray adsorption at the $L_{3} 2$ $p_{3 / 2}$ subshell of mercury, at $12,284.0$ $\mathrm{eV}$, can be discerned as shown in the inset to Fig. 6. This mercury in the semiconducting boron carbide is unlikely to be at the surface as after $\mathrm{Hg}$ exposure the sample is placed under vacuum and gently annealed for hours above room temperature ( $340 \mathrm{~K})$.

Since this boron carbide semiconducting material is an icosahedral network of largely dehydrogenated carborane, there are more opportunities for $\mathrm{Hg}$ chemical bond formation, such as the those $\mathrm{Hg}$ bonds formed in the mercury bridge bonded carborane species [50] described above. The interactions between mercury and orthocarborane icosahedra are now less likely to be repulsive in nature, as described above. When the molecules are largely dehydrogenated in a thin solid film, the icosahedra cannot pack in a solid structure to compensate all the apical main group (boron and carbon) atom binding sites and a space filling lattice is not possible.
Forming a boron carbide film through plasma enhanced chemical vapor deposition of orthocarborane [17, $22,23]$ certainly results in substantial dehydrogenation of the orthocarborane source molecule. Through this PECVD process, a high quality semiconducting boron carbide film can be formed undoped with any transition metal, with the temperature dependence of a good semiconductor, as indicated in Fig. 7a, with two temperature regions with clearly very different transport behavior. The two distinct slopes in the conductivity, plotted in Fig. 7, correspond to a conduction mechanism dominated by intrinsic carriers at high temperature and extrinsic carriers at low temperature, that can be associated with the intrinsic carriers from the semiconducting boron carbide, and extrinsic carriers injected into the semiconducting boron carbide, that become more readily apparent as intrinsic carrier conduction freezes [12].

The logarithm of inverse of the resistance, as a function of reciprocal temperature, shows that such boron carbide exhibits typical semiconductor temperature dependent conductivity with increased resistance at lower temperatures for the measurements undertaken before and after mercury exposure. The slopes of the two regions decrease, to some extent for the sample containing mercury, indicating a decrease in activation energy for transport. Nonetheless, both before and after $\mathrm{Hg}$ exposure and absorption into the semiconducting boron carbide film, the film remains highly resistive $\left(10^{9}\right.$ to $10^{10} \mathrm{Ohm} \mathrm{cm}$ is typical $[22,29$, 30]). This may indicate that the inter action between boron carbide film and

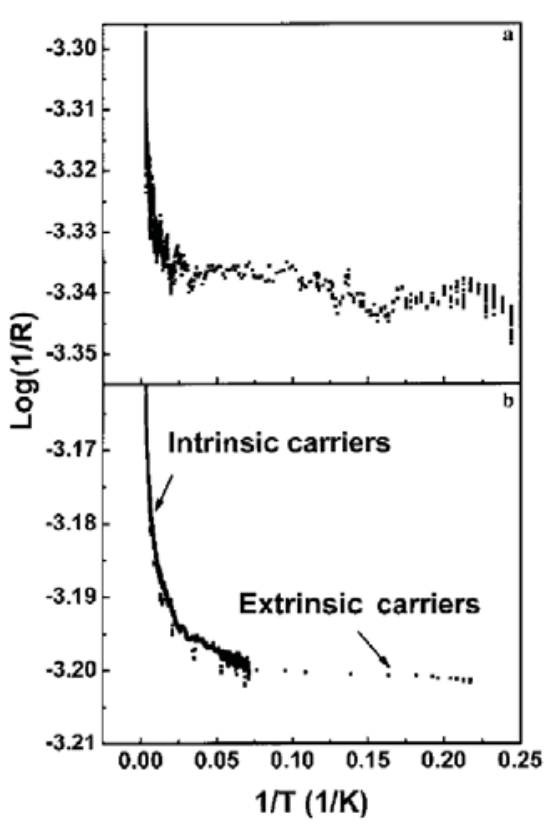

FIGURE 7 The logarithmic function of inverse of the measured resistance as a function of the inverse of temperature for the film before (a) and after (b) mercury exposure. The two distinct regions correspond to intrinsic carriers at high temperature, and extrinsic carriers at low temperature, respectively (see text).

mercury is now quite strong, and any possible additional carriers introduced by $\mathrm{Hg}$ are quite localized.

Generally, $\mathrm{Hg}$ is a poor conventional dopant for semiconducting boron carbide as the $\mathrm{Hg}$ incorporation does not lead to a significant increase in carriers and may, in fact, lead to a small decrease in carriers. In this regard, $\mathrm{Hg}$ doping is very different from the $3 d$ transition metal dopants which result in a significant decrease in resistivity and a semiconductor material increasingly dominated by donor states that accumulate with higher doping concentrations [19-23]. For a resistive device, such as might be used in low neutron flux pulse counting, $\mathrm{Hg}$ doping may nonetheless have potential applications. $\mathrm{Hg}$ as a dopant in semiconducting boron carbide is much like the behavior for $\mathrm{Hg}$ doping of $\mathrm{CdTe}$ (another material considered for use in solid state nuclear radiation detectors) where $\mathrm{Hg}$ doping leads to an increase in resistivity [52].

\section{Conclusions}

Weak hybridization between the mercury $5 d$ core level and the molecular 
orthocarborane clusters is apparent from photoemission. Exposure of semiconducting boron carbide to mercury suggests that a small amount of mercury may, however, interact with the solid films of the dehydrogenated $\mathrm{C}_{2} \mathrm{~B}_{10}$ icosahedra (semiconducting boron carbide). This interaction is different from any expectation that would result from the very weak interaction observed between mercury $(\mathrm{Hg})$ and the molecular (hydrogenated $\mathrm{C}_{2} \mathrm{~B}_{10}$ ) orthocarborane. In terms of doping, inclusion of $\mathrm{Hg}$ in semiconducting boron carbide has only a minor influence on the resistance, resulting in a slight increase in resistance and a slight decrease in thermal activation.

ACKNOWLEDGEMENTS - This research was supported by the National Science Foundation through grants \#ECS-0300018, and \#EPS0091909, the Office of Naval Research, with partial funding provided by the U.S. Department of Energy National Nuclear Security Administration Office of Nonproliferation Research and Engineering (NA-22) in collaboration with Pacific Northwest National Laboratory. The Synchrotron Radiation Center is funded by the NSF, while the Center for Advanced Microstructures and Devices is funded by the State of Louisiana. The authors would like to thank David McIlroy for his technical assistance with some of the measurements reported here.

\section{REFERENCES}

1 B.W. Robertson, S. Adenwalla, A. Harken, P. Welsch, J.I. Brand, P.A. Dowben, J.P. Claassen, Appl. Phys. Lett. 80, 3644 (2002)

2 B.W. Robertson, S. Adenwalla, A. Harken, P. Welsch, J.I. Brand, J.P. Claassen, N.M. Boag, P.A. Dowben, Advances in Neutron Scattering Instrumentation, ed. by I.S. Anderson, B. Gúerard, Proc. SPIE 4785, 226 (2002)

3 S. Adenwalla, R. Billa, J.I. Brand, E. Day, M.J. Diaz, A. Harken, A. McMullen-Gunn, R. Padmanabhan, B.W. Robertson, Proc. SPIE 5199, 70 (2003)

4 A.N. Caruso, R.B. Billa, S. Balaz, J.I. Brand, P.A. Dowben, J. Phys.: Condens. Matter 16, L139 (2004)

5 A.D. Harken, E.E. Day, B.W. Robertson, S Adenwalla, Jpn. J. Appl. Phys. 44, 444 (2005)

6 D.N. Mcllroy, J. Phys.: Condens. Matter 16, V13 (2004)

7 Z.W. Bell, D.A. Carpenter, S.S. Cristy, V.E. Lamberti, A. Burger, B.F. Woodfield, T. Niedermayr, I.D. Hau, S.E. Labov, S. Friedrich, W.G. West, K.R. Pohl, L. van der Berg, Phys. Status Solidi c2, 1592 (2005)
8 A. Owens, A. Peacock, Nucl. Instrum. Methods Phys. Res., Sect. A 531, 18 (2004)

9 P.M. Martin, Vac. Coat. Technol. 6 (2004)

10 Y. Kasugai, F. Maekawa, Y. Ikeda, H. Takeuchi, J. Nucl. Sci. Technol. 38, 1048 (2001)

11 P.P. Edwards, J.L. Johnston, F. Hensel, C.N.R. Rao, D.P. Tunstall, Solid State Phys. -Adv. Res. Appl. 52, 229 (1999)

12 N.F. Mott, Nonmetal to Metal Transitions (Taylor \& Francis, London 1990)

13 P.A. Dowben, Surf. Sci. Rep. 40, 151 (2000)

14 D.N. McIlroy, C. Waldfried, T. McAvoy, J. Choi, P.A. Dowben, D. Heskett, Chem. Phys. Lett. 264, 168 (1997)

15 D.N. McIlroy, J. Zhang, P.A. Dowben, D. Heskett, Mater. Sci. Eng. A 217/218, 64 (1996)

16 D.N. McIlroy, J. Zhang, P.A. Dowben, P. Xu, D. Heskett, Surface Science 328, 47 (1995)

17 S.-D. Hwang, K. Yang, P.A. Dowben, A.A. Ahmad, N.J. Ianno, J.Z. Li, J.Y. Lin, H.X. Jiang, D.N. Mcllroy, Appl. Phys. Lett. 70, 1028 (1997)

18 H. Takizawa, N. Haze, K. Okamoto, K. Uheda, T. Endo, Mater. Res. Bull. 37, 113 (2002)

19 U. Kuhlmann, H. Werheit, J. Pelloth, W. Keune, T. Lundstrom, Phys. Status Solidi B 187, 43 (1995)

20 U. Kuhlmann, H. Werheit, T. Dose, T. Lundstrom, J. Alloys Compd. 186, 187 (1992)

21 H. Werheit, R. Schmechel, V. Kueffel, T. Lundstrom, J. Alloys Compd. 262, 372 (1997)

22 D.N. McIlroy, S.-D. Hwang, K. Yang, N. Remmes, P.A. Dowben, A.A. Ahmad, N.J. Ianno, J.Z. Li, J.Y. Lin, H.X. Jiang, Appl. Phys. A 67, 335 (1998)

23 S.-D. Hwang, N.B. Remmes, P.A. Dowben, D.N. McIlroy, J. Vac. Sci. Technol. B 14, 2957 (1996)

24 S.-D. Hwang, N. Remmes, P.A. Dowben, D.N. Mcllroy, J. Vac. Sci. Technol. A 15, 854 (1997)

25 P. Lunca-Popa, J.I. Brand, S. Balaz, L.G. Rosa, N.M. Boag, M. Bai, B.R. Robertson, P.A. Dowben, J. Phys. D: Appl. Phys. 38, 1248 (2005)

26 A.N. Caruso, S. Balaz, B. Xu, P.A. Dowben, A.S. McMullen-Gunn, J.I. Brand, Y.B. Losovyj, D.N. McIlroy, Appl. Phys. Lett. 84, 1302 (2004)

27 H. Zeng, D. Byun, J. Zhang, G. Vidali, M. Onellion, P.A. Dowben, Surf. Sci. 313, 239 (1994)

28 C.C. Ilie, P. Lunca-Popa, J. Zhang, B. Doudin, P.A. Dowben, Mater. Res. Soc. Symp. Proc. 848, FF6.5.1 (2005)

29 S. Lee, P.A. Dowben, Appl. Phys. A 58, 223 (1994)

30 S. Lee, J. Mazurowski, G. Ramseyer, P.A. Dowben, J. Appl. Phys. 72, 4925 (1992)

31 J.J.P. Stewart, J. Comput. Chem. 10, 209 (1989)
32 J.J.P. Stewart, J. Comput. Chem. 10, 221 (1989)

33 A.N. Caruso, L. Bernard, B. Xu, P.A. Dowben, J. Phys. Chem. B 107, 9620 (2003)

34 D. Byun, S-D. Hwang, J. Zhang, H. Zeng, F.K. Perkins, G. Vidali, P.A. Dowben, Jpn. J. Appl. Phys. Lett. 34, L941 (1995)

35 S. Balaz, Ya.B. Losovyj, P.A. Dowben, in preparation 36 M. Onellion, Y.J. Kime, P.A. Dowben, N. Tache, J. Phys. C: Solid State Phys. 20, L633 (1987)

37 P.A. Dowben, S. Varma, Y.J. Kime, D.R. Mueller, M. Onellion, Z. Phys. B73, 247 (1988)

38 B. Xu, C.N. Borca, S. Ducharme, A.V. Sorokin, P.A. Dowben, V.M. Fridkin, S.P. Palto, N. Petukhova, S.G. Yudin, J. Chem. Phys. 114, 1866 (2001)

39 B. Xu, J. Choi, C.N. Borca, A.V. Sorokin, P.A. Dowben, S.P. Palto, N. Petukhova, S.G. Yudi, Appl. Phys. Lett. 78, 448 (2001)

40 B. Xu, J. Choi, A.N. Caruso, P.A. Dowben, Appl. Phys. Lett. 80, 4342 (2002)

41 P. Dannetun, M. Lögdlund, C. Fredriksson, R. Lazzaroni, C. Fauquet, S. Stafström, C.W. Spangler, J.L. Brédas, W.R. Salaneck, J. Chem. Phys. 100, 6765 (1994)

42 P. Dannetun, M. Boman, S. Stafström, W.R. Salaneck, R. Lazzaroni, C. Fredriksson, J.L. Brédas, R. Zamboni, C. Taliani, J. Chem. Phys. 99, 664 (1993)

43 M. Fahlman, J.L. Brédas, W.R. Salaneck, Synth. Met. 78, 237 (1996)

44 P.S. Ho, P.O. Hahn, J.W. Bartha, G.W. Rubloff, F.K. LeGoues, B.D. Silverman, J. Vac. Sci. Technol. A 3, 739 (1985)

45 M. Lögdlund, R. Lazzaroni, S. Stafström, W.R. Salaneck, J.L. Brédas, Phys. Rev. Lett. 63, 1841 (1989)

46 M. Fahlman, D. Beljonne, M. Lögdlund, R.H. Friend, A.B. Holmes, J.L. Brédas, W.R. Salaneck, Chem. Phys. Lett. 214, 327 (1993)

47 M. Lögdlund, P. Dannetun, S. Stafström, W.R. Salaneck, M.G. Ramsey, C.W. Spangler, C. Fredricksson, J.L. Brédas, Phys. Rev. Lett. 70, 970 (1993)

48 T. Miyamae, D. Yoshimura, H. Ishii, Y. Ouchi, T. Miyazaki, T. Koike, T. Yamamoto, K. Seki, J. Electron. Spectrosc. Relat. Phenom. 78, 399 (1996)

49 J. Choi, P.A. Dowben, C.N. Borca, Shireen Adenwalla, A.V. Bune, S. Ducharme, V.M Fridkin, S.P. Palto, N. Petukhova, Phys. Rev. B 59, 1819 (1999)

50 Z. Zheng, M. Diaz, C.B. Knobler, M. Frederick Hawthorne, J. Am. Chem. Soc. 117, 12338 (1995)

51 S.-D. Hwang, D. Byun, N.J. Ianno, P.A. Dowben, H.R. Kim, Appl. Phys. Lett. 68, 1495 (1996)

52 E. Saucedo, L. Fornaro, N.V. Sochinskii, A. Cuna, D. Granados, E. Dieguez, IEEE Trans. Nucl. Sci. 51, 3105 (2004) 